\title{
openheart C-arm rotation as a method for reducing peak skin dose in interventional cardiology
}

\author{
Alexander S Pasciak, ${ }^{1}$ Austin C Bourgeois, ${ }^{1}$ A Kyle Jones ${ }^{2}$
}

To cite: Pasciak AS, Bourgeois AC, Jones AK. $\mathrm{C}$-arm rotation as a method for reducing peak skin dose in interventional cardiology. Open Heart 2014;1:e00141 doi:10.1136/openhrt-2014000141

Received 5 May 2014 Revised 28 July 2014 Accepted 4 November 2014

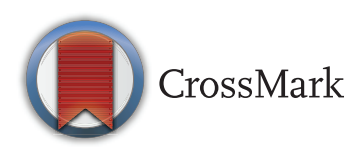

${ }^{1}$ Department of Radiology, University of Tennessee Medical Center, Knoxville, Tennessee, USA

${ }^{2}$ Department of Imaging Physics, The University of Texas MD Anderson Cancer Center, Houston, Texas, USA

Correspondence to Dr A Kyle Jones,

kyle.jones@mdanderson.org

\section{ABSTRACT}

Purpose: Prolonged interventional cardiology (IC) procedures may result in radiation-induced skin injury, a potentially preventable cause of patient morbidity. Rotating the C-arm during an IC procedure may reduce this risk, although the methods by which the technique can be practically applied remains unexplored.

A previous study demonstrated that C-arm rotation often increases peak skin dose (PSD) in interventional radiology procedures. The purpose of this study was to determine whether C-arm rotation reduces the PSD in IC procedures and, if so, under what circumstances.

Materials and methods: Simulations were performed using a numerical ray-tracing algorithm to analyse the effect of C-arm rotation on PSD across a range of patient sizes, $\mathrm{C}$-arm configurations and procedure types. Specific data from modern fluoroscopes and patient dimensions were used as inputs to the simulations.

Results: In many cases, modest C-arm rotation angles completely eliminated overlap between X-ray field sites on the skin. When overlap remained, PSD increases were generally small. One exception was craniocaudal rotation, which tended to increase PSD. $\mathrm{C}$-arm rotation was most effective for large patients and small $\mathrm{X}$-ray field sizes. Small patients may not benefit from $\mathrm{C}$-arm rotation as a procedural modification. The use of a prophylactic method where the $\mathrm{C}$-arm was rotated between small opposing oblique angles was effective in reducing PSD.

Conclusions: With the exception of rotation to steep craniocaudal angles, rotating the C-arm reduces PSD in IC procedures when used as either a procedural modification or a prophylactic strategy. Tight collimation increases the benefit of $\mathrm{C}$-arm rotation.

\section{INTRODUCTION}

Prolonged exposure to ionising radiation from fluoroscopically guided interventions (FGI) carries with it a number of known risks. Among these risks, the most immediately debilitating and clearly attributable to radiation exposure are radiation-induced tissue effects, including damage to skin and bone tissue. ${ }^{1-7}$ Fortunately, tissue effects from lengthy FGI are relatively uncommon in interventional

\section{KEY QUESTIONS}

What is already known about this subject?

- It is widely taught in medical disciplines which use fluoroscopy to diagnose and treat disease that rotation of the $\mathrm{C}$-arm during lengthy interventions can decrease patient dose, potentially preventing radiation-induced skin injury. However, there is no detailed guidance as to how this practice should be most effectively executed in interventional cardiology.

What does this study add?

- This study examines many common cases in interventional cardiology and the effect of C-arm rotation on patient dose. Patient size, common views, direction of rotation as well as field size and shape are all considered. A summary is presented which put the findings in a clinical context likely to be useful for interventional cardiologists.

How might this impact on clinical practice?

- With the information presented, interventional cardiologists will understand the effect of $\mathrm{C}$-arm rotation on patient dose. They will learn the cases where C-arm rotation is beneficial at reducing patient dose and cases where it is contraindicated and may actually increase patient dose. This knowledge may be beneficial to physicians who perform lengthy cardiac interventions.

cardiology (IC). This is at least partly because the most common IC procedure, percutaneous coronary intervention (PCI) for ischaemic revascularisation, ${ }^{8}$ is unlikely to result in peak skin doses (PSDs) sufficient to cause radiation-induced tissue effects except in rare cases. Several studies have reported typical skin doses for IC procedures, including a range of PSD from 630 to $2840 \mathrm{mGy}$ for percutaneous transluminal angioplasty (PTCA) at multiple centres $;^{9}$ a range of entrance surface doses from 770 to $1210 \mathrm{mGy}$ for radiofrequency ablation, $180-550 \mathrm{mGy}$ for coronary angiography and 460-1021 mGy for PTCA; ${ }^{10}$ and mean PSD of $351 \mathrm{mGy}$ for coronary angiography, $1304 \mathrm{mGy}$ for PCI, $513 \mathrm{mGy}$ for RF ablation, 
344 mGy for coronary angiography+left ventriculogram, and $1606 \mathrm{mGy}$ for PTCA+stenting. ${ }^{11}$ A comprehensive review by Koenig et a $\vec{l}$ examined 47 cases of radiationinduced tissue effects after IC procedures from 1996 to 2000. Of these cases, three patients underwent diagnostic coronary angiography only, while the remaining 44 had additional PTCA. Considering the large number of coronary interventions occurring in the USA each year, these injuries are rare. However, many similar cases go unreported, and many cases that are reported are not included in reviews owing to a lack of dosimetry data or ongoing legal proceedings. ${ }^{3}$ However, recent advances have increased the scope and complexity of IC procedures, sometimes necessitating lengthy fluoroscopic imaging or serial FGI. Complex PCI, transcatheter aortic valve replacement (TAVR), and electrophysiology (EP) procedures may expose patients to clinically significant doses of radiation, particularly in the setting of intraprocedural complication, patient obesity or operator inexperience. ${ }^{12}$ Aside from 11 reported cases of injury from EP procedures performed from 1996 to $2000^{3}$ there is little available data regarding the frequency of injury resulting from these more complex procedures.

Radiation-induced skin changes are the most common manifestation of tissue damage associated with FGI. These changes range from mild grade 1 reactions such as transient erythema at low doses (ie, 5-10 Gy) to severe grades 3-4 reactions such as ulceration and necrosis at high doses (ie, $>15 \mathrm{~Gy}){ }^{1}{ }^{1}$ Efforts to reduce the incidence of skin injury have been the subject of extensive prior research resulting in several proposed methods for reducing the PSD in IC procedures. ${ }^{13-17}$ These techniques include tight collimation of the X-ray field, low magnification, reducing the source-to-image distance and use of pulsed fluoroscopy mode. Changing $\mathrm{C}$-arm position during the procedure to distribute radiation over a larger skin surface area is one such method that is often recommended to reduce PSD ${ }^{13}{ }^{15-17}$ and this recommendation has been generalised as potentially beneficial in all FGI. ${ }^{15-17}$ However, a recent report demonstrated that $\mathrm{C}$-arm rotation during interventional radiology (IR) procedures is beneficial only in specific circumstances and counterproductive in others, ${ }^{18}$ raising questions regarding the validity of C-arm rotation as a dose reduction strategy in IC.

Differences in technique and imaging geometry prevent the direct application of conclusions regarding C-arm rotation drawn for $\mathrm{IR}^{18}$ to IC. During IC procedures, the patient's heart is typically positioned at or near the isocenter of the fluoroscope. Such positioning results in radiographic magnification factors that are larger than those used in IR procedures. Owing to these geometric differences and the smaller X-ray fields used in IC procedures, the effect of C-arm rotation on PSD may be different in IC procedures than in IR procedures. The influence of $\mathrm{C}$-arm angle on patient and operator dose has been studied for IC procedures, ${ }^{19}$ however, the effects on PSD of the use of multiple angles has not been critically evaluated.

The purpose of the present investigation was to determine if $\mathrm{C}$-arm rotation provides benefit for reducing PSD in IC procedures and under what circumstances this technique is most effective, thereby providing a practical framework for clinical implementation.

\section{METHODS}

A numerical simulation engine based on ray tracing for radiation transport theory ${ }^{20}$ was used to compute skin dose maps for each simulated case. The validity of this simulation has been verified independently elsewhere. ${ }^{18}$

Two C-arm fluoroscopes were simulated: one was a flat-panel system (Artis zee, Siemens Medical Systems, Malvern, Pennsylvania, USA) with a $48 \mathrm{~cm}$ A-plane detector and a $25 \mathrm{~cm}$ B-plane detector, and the other was an X-ray image-intensified (XRII) system (Integris H5000F, Phillips Medical Systems, Andover, Massachusetts, USA) with a 9-inch XRII. Because large image receptors are unusual in cardiology, only data acquired using the B-plane detector on the Artis zee system were used in this study. The X-ray field sizes (formats) that were available on the two simulated systems are listed in table 1 . To facilitate interpretation of data, similar formats were grouped as indicated in the 'Format group' column in table 1.

\section{Patient simulation}

Patients were simulated as elliptical cylinders as described in a previous study of $\mathrm{C}$-arm rotation in IR procedures. ${ }^{18}$ PeopleSize 2008 (Open Ergonomics Ltd, Leicestershire, UK), an anthropometric database, was used to calculate stylised patient dimensions. Anteroposterior and lateral thoracic dimensions were downloaded from PeopleSize 2008 for the 5th, 10th, 25th, 50th, 75th, 90th and 95th centiles of 18-64-year-old male and female patients in the

Table 1 Formats available for the two fluoroscopic systems simulated in this study and grouping of the formats as presented in figures in this work

\begin{tabular}{lllll}
\hline Format & Siemens Artis zee* $\mathbf{( c m )}$ & Format group & Philips Integris H5000F† $(\mathbf{c m})$ & Format group \\
\hline 1 (Zoom/Mag 0) & 25 & $\mathrm{~A}$ & $22.5\left(9^{\prime \prime}\right)$ & $\mathrm{A}$ \\
2 (Zoom/Mag 1) & 20 & $\mathrm{~A}$ & $17.5\left(7^{\prime \prime}\right)$ & $\mathrm{B}$ \\
3 (Zoom/Mag 2) & 16 & $\mathrm{~B}$ & $12.5\left(5^{\prime \prime}\right)$ & $\mathrm{C}$ \\
4 (Zoom/Mag 3) & 10 & $\mathrm{C}$ & - & \\
\hline Sizes are quoted as the diagonal of the field. & & & \\
"Square fields. \\
TOctagonal fields.
\end{tabular}


Table 2 Patient sizes simulated in this study

\begin{tabular}{|c|c|c|c|c|c|}
\hline $\begin{array}{l}\text { Size } \\
\text { group }\end{array}$ & $\begin{array}{l}\text { Population } \\
\text { percentile }\end{array}$ & $\begin{array}{l}\text { Male AP } \\
\text { dimension }(\mathrm{cm})\end{array}$ & $\begin{array}{l}\text { Male trans } \\
\text { dimension }(\mathrm{cm})\end{array}$ & $\begin{array}{l}\text { Female AP } \\
\text { dimension }(\mathrm{cm})\end{array}$ & $\begin{array}{l}\text { Female trans } \\
\text { dimension }(\mathrm{cm})\end{array}$ \\
\hline & 5 & 23.8 & 28.4 & 22.8 & 22.8 \\
\hline \multirow[t]{2}{*}{ Small } & 10 & 24.9 & 29.4 & 23.8 & 23.5 \\
\hline & 25 & 26.8 & 31.0 & 25.8 & 24.6 \\
\hline \multirow[t]{2}{*}{ Average } & 50 & 29 & 32.9 & 28.5 & 25.8 \\
\hline & 75 & 31.4 & 34.7 & 31.7 & 27.1 \\
\hline \multirow[t]{2}{*}{ Large } & 90 & 33.8 & 36.5 & 35.2 & 28.3 \\
\hline & 95 & 35.4 & 37.5 & 37.2 & 29.0 \\
\hline
\end{tabular}

USA, and dimensions for other sizes were calculated using cubic Hermite spline interpolation of the PeopleSize 2008 data. Patients were categorised into three-size groups as described in a previous study (table 2). ${ }^{18}$

\section{Patient positioning}

A waiver of informed consent was granted by the Institutional Review Board for this portion of our study. The location of the entrance surface of the skin depends not only on the position of the heart with respect to the isocenter but also on the location of the heart within the patient's chest. A series of 40 (20 men and 20 women) chest CT scans of patients in good cardiovascular health was reviewed, and the transverse and anterior distances of the midpoint of the heart from the centre of the chest were measured. These data were used to position the simulated patients; for men, the heart was positioned at $5.1 \mathrm{~cm}$ anterior and $2.7 \mathrm{~cm}$ left of the midline, and for women, the heart was positioned at $4.2 \mathrm{~cm}$ anterior and $2.5 \mathrm{~cm}$ left of the midline.

\section{C-arm rotation as a procedural modification}

A number of primary projections common to IC were studied, ${ }^{21}$ these are listed in table 3 . The angle to avoid overlap (AAO), the minimum rotation angle necessary to completely avoid overlap of X-ray field sites on a patient's skin, was calculated as a function of patient size and format group. The PSD was calculated as a function of $\mathrm{C}$-arm angle for each permutation of patient and format group. X-ray tube output was calculated using a lookup table constructed from measured automatic exposure control curves. The rate of dose accumulation in each area on the skin surface was calculated on the basis of the source-to-skin distance (SSD), X-ray tube output and published tables of backscatter factors (BSF). ${ }^{22}$ PSD plots were created by dividing the irradiation time equally between the primary and rotated projections. PSD was plotted relative to the PSD that would have been reached with no $\mathrm{C}$-arm rotation.

\section{C-arm rotation as a prophylactic measure}

In another set of simulations, the C-arm was rotated between two opposing projections in the RAO/LAO and CRA/CAU directions. This technique has been described as a strategy to reduce PSD in $\mathrm{IR}^{18}$ and EP procedures. ${ }^{23}$ The AAO was calculated for RAO/LAO rotation and CRA/CAU rotation.

\section{RESULTS}

Figure 1 is an example of the PSD plots used to extract clinically relevant data from this study. In figure 1, a simulated procedure is performed on an average-sized patient using an isocentric geometry with an initial posteroanterior (PA) projection. A relative PSD of less than 1.0 indicates that rotation to an oblique projection reduced PSD when compared to performing the entire procedure using a PA projection, while a value greater than 1.0 indicates that rotation to an oblique projection increased PSD. A clear point is apparent at angles greater than either $26^{\circ} \mathrm{RAO}$ or $22^{\circ} \mathrm{LAO}$ where a reduction in PSD is realised owing to lack of X-ray field overlap between the $\mathrm{PA}$ and rotated projection. These are the AAO.

\section{C-arm rotation as a procedural modification}

Depending on patient size and X-ray field size and format, rotation in the $\mathrm{LAO}$ direction from $12^{\circ}$ to $32^{\circ}$

Table 3 Procedural modifications simulated

\begin{tabular}{|c|c|c|}
\hline Simulation & $\begin{array}{l}\text { Initial } \\
\text { projection }\end{array}$ & Rotation \\
\hline $\begin{array}{l}\text { Rotation from initial PA } \\
\text { projection }\end{array}$ & PA & $\begin{array}{l}\text { LAO, RAO, } \\
\text { CRA, CAU }\end{array}$ \\
\hline \multirow[t]{3}{*}{$\begin{array}{l}\text { Rotation from initial } \\
\text { LAO/RAO projection }\end{array}$} & $30^{\circ}$ LAO & $\begin{array}{l}\text { LAO, RAO, } \\
\text { CRA, CAU }\end{array}$ \\
\hline & $60^{\circ} \mathrm{LAO}$ & $\begin{array}{l}\text { RAO, CRA, } \\
\text { CAU }\end{array}$ \\
\hline & $30^{\circ} \mathrm{RAO}$ & $\begin{array}{l}\text { LAO, RAO, } \\
\text { CRA, CAU }\end{array}$ \\
\hline \multirow[t]{2}{*}{$\begin{array}{l}\text { Rotation from initial } \\
\text { compound projection }\end{array}$} & $\begin{array}{l}60^{\circ} \mathrm{LAO}+30^{\circ} \\
\mathrm{CRA}^{*}\end{array}$ & $\begin{array}{l}\text { RAO, CRA, } \\
\text { CAU }\end{array}$ \\
\hline & $\begin{array}{l}30^{\circ} \text { RAO }+30^{\circ} \\
\text { CRAt }\end{array}$ & $\begin{array}{l}\text { LAO, RAO, } \\
\text { CRA, CAU }\end{array}$ \\
\hline
\end{tabular}

${ }^{*}$ Often used to visualise left main stem and distal LAD coronary arteries. ${ }^{18}$

†Often used to visualise the middle segment of the LAD. ${ }^{18}$

$C A U$, caudal; CRA, cranial; LAD, left anterior descending; LAO, left anterior oblique; PA, posteroanterior; RAO, right anterior oblique. 


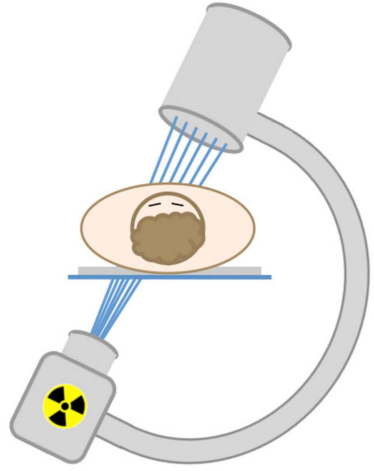

Spreading dose between PA and RAO angles exceeding $26^{\circ}$ decreases PSD by a factor of 2 compared with PA alone. This is the AAO.

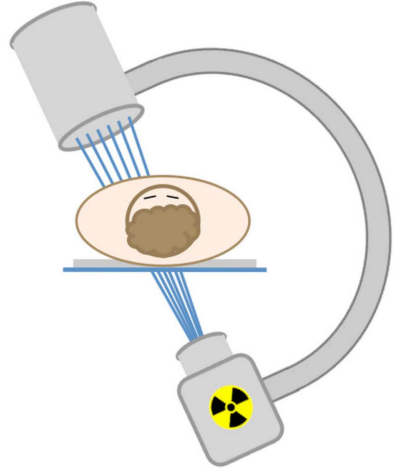

Spreading dose between PA and LAO angles exceeding $22^{\circ}$ decreases PSD by a factor of 2 compared with PA alone. This is the AAO.

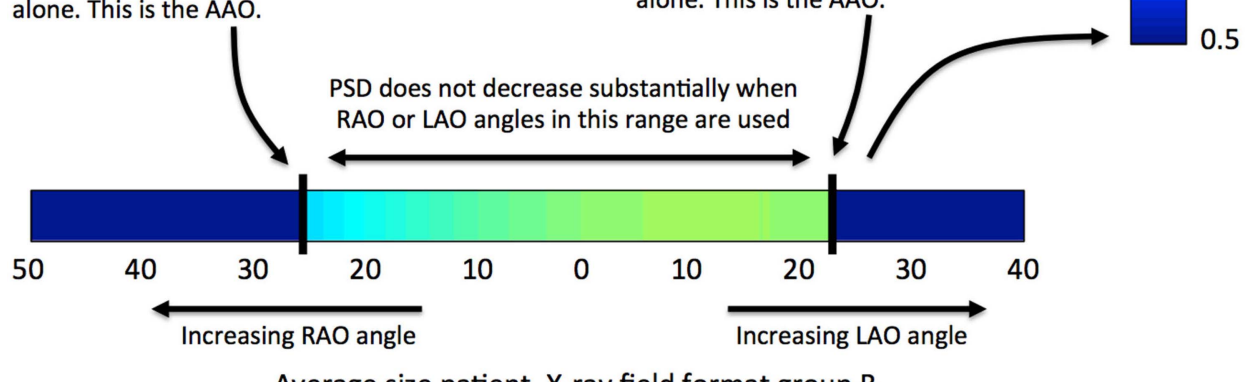

Average size patient, $\mathrm{X}$-ray field format group $\mathrm{B}$

Figure 1 Use of the PSD plots to extract clinically relevant information (AAO, angle to avoid overlap; PSD, peak skin dose; $\mathrm{LAO}$, left anterior oblique; PA, posteroanterior; RAO, right anterior oblique).

and in the RAO direction from $14^{\circ}$ to $40^{\circ}$ was necessary to completely avoid overlap with an initial PA projection (figure 2A). In general, RAO rotation required a slightly larger AAO owing to the location of the heart to the left of midline. However, the difference was too small to be clinically meaningful. The use of larger X-ray fields resulted in larger AAO, as did smaller patient size. Less rotation was required to avoid overlap for male patients than for female patients. This finding held true for all patients except very large patients, for which male and female patients were approximately the same size.

Even when primary and secondary projections overlapped, increases in PSD were small (figure 2A).
Once the AAO was reached, the PSD decreased to approximately $50 \%$ of the PSD at the PA projection. However, the PSD increased substantially when the C-arm was rotated in the CRA/CAU direction, even if the primary and secondary projections did not overlap (figure 2B). The PSD increase for CRA/CAU rotation for the smallest patients can be $100 \%$ higher than use of a PA projection alone (figure $2 \mathrm{~B}$ ). In this case, CRA/ CAU rotation results in decreased PSD only for large patients and small X-ray field sizes (figure 2B).

Similar results were found for rotation starting from an initial $30^{\circ} \mathrm{LAO}$ or RAO projection and rotation from a steeper $60^{\circ} \mathrm{LAO}$ angle (figure 3).
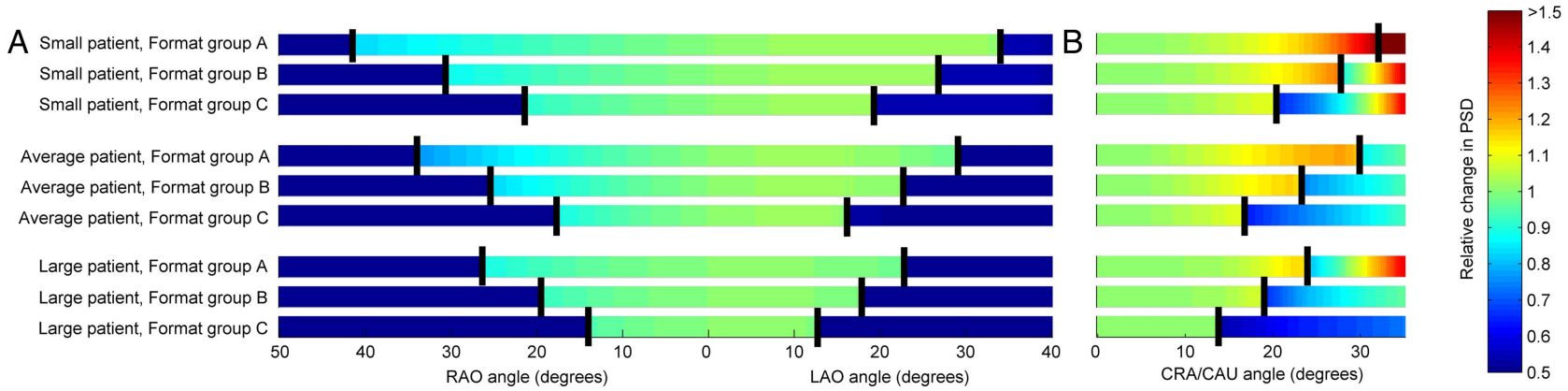

Figure 2 The effect of rotation from a primary PA projection on PSD for female patients: (A) LAO/RAO rotation and (B) CRA/ CAU rotation. Vertical bold lines indicating the AAO. The results for each format group represent the X-ray field format and size from the group that required the largest AAO (AAO, angle to avoid overlap; PSD, peak skin dose; CAU, caudal; CRA, cranial; $\mathrm{LAO}$, left anterior oblique; PA, posteroanterior; RAO, right anterior oblique). 

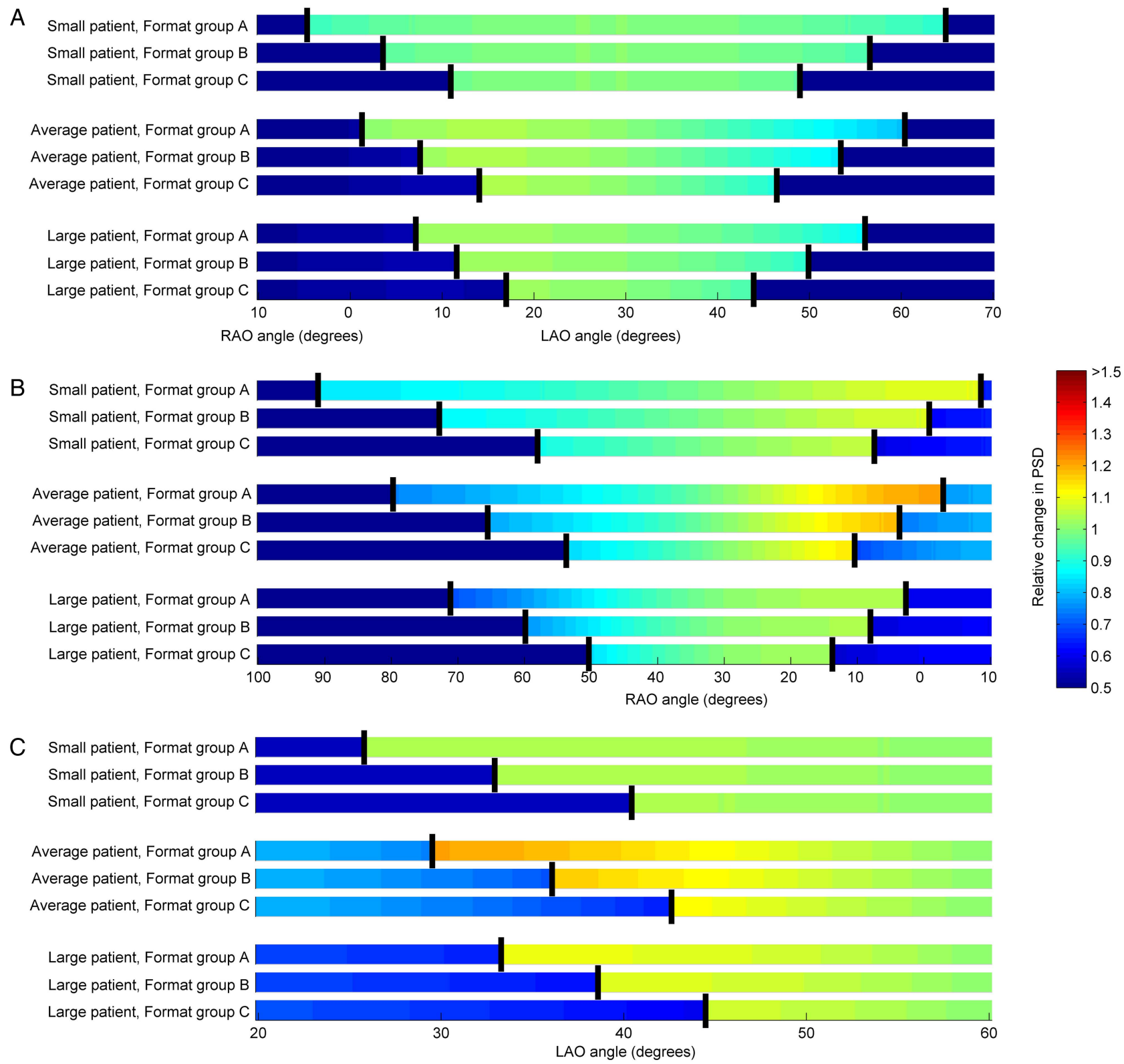

Figure 3 The effect of rotation from a primary LAO or RAO angle on PSD for female patients: (A) primary $30^{\circ} \mathrm{LAO}$ projection; (B) primary $30^{\circ} \mathrm{RAO}$ projection and (C) primary $60^{\circ} \mathrm{LAO}$ projection. Results of CRA/CAU rotation from an initial $30^{\circ}$ or $60^{\circ} \mathrm{LAO}$ projection were nearly identical to CRA/CAU rotation from a PA projection and are not shown. Vertical bold lines indicating the AAO. The results for each format group representing the $X$-ray field format and size from the group that required the largest AAO (AAO, angle to avoid overlap; PSD, peak skin dose; CAU, caudal; CRA, cranial; LAO, left anterior oblique; RAO, right anterior oblique).

When starting with a compound projection of $60^{\circ} \mathrm{LAO}$ $+30^{\circ}$ CRA, $12-30^{\circ}$ of rotation in the RAO direction was required to eliminate overlap (figure $4 \mathrm{~A}$ ). Larger CAU angles ranging from $10^{\circ}$ to $40^{\circ}$ were required to achieve the same effect. CAU rotation was very effective at reducing the PSD in the case of an initial compound projection with a large CRA component, owing to the fact that the tissue penetration thickness along the beam path was reduced. In fact, PSD was reduced even when the AAO was not reached. When starting with a compound projection of $30^{\circ} \mathrm{RAO}+30^{\circ} \mathrm{CRA}, 13-35^{\circ}$ of $\mathrm{LAO}$ rotation eliminated overlap, whereas up to $50^{\circ}$ of RAO rotation was required to achieve the same effect (figure 4B).

\section{C-arm rotation as a prophylactic measure}

Rotation between $8^{\circ} \mathrm{LAO}$ and $8^{\circ} \mathrm{RAO}$ projections was sufficient to avoid overlap for average-sized patients for the smallest format group (figure 5A). Larger angles were required for larger X-ray fields; however, angles of $16^{\circ}$ and $18^{\circ}$ were sufficient to eliminate overlap for the smallest male and female patients, respectively, for the largest format group. Slightly larger opposing CRA/CAU 

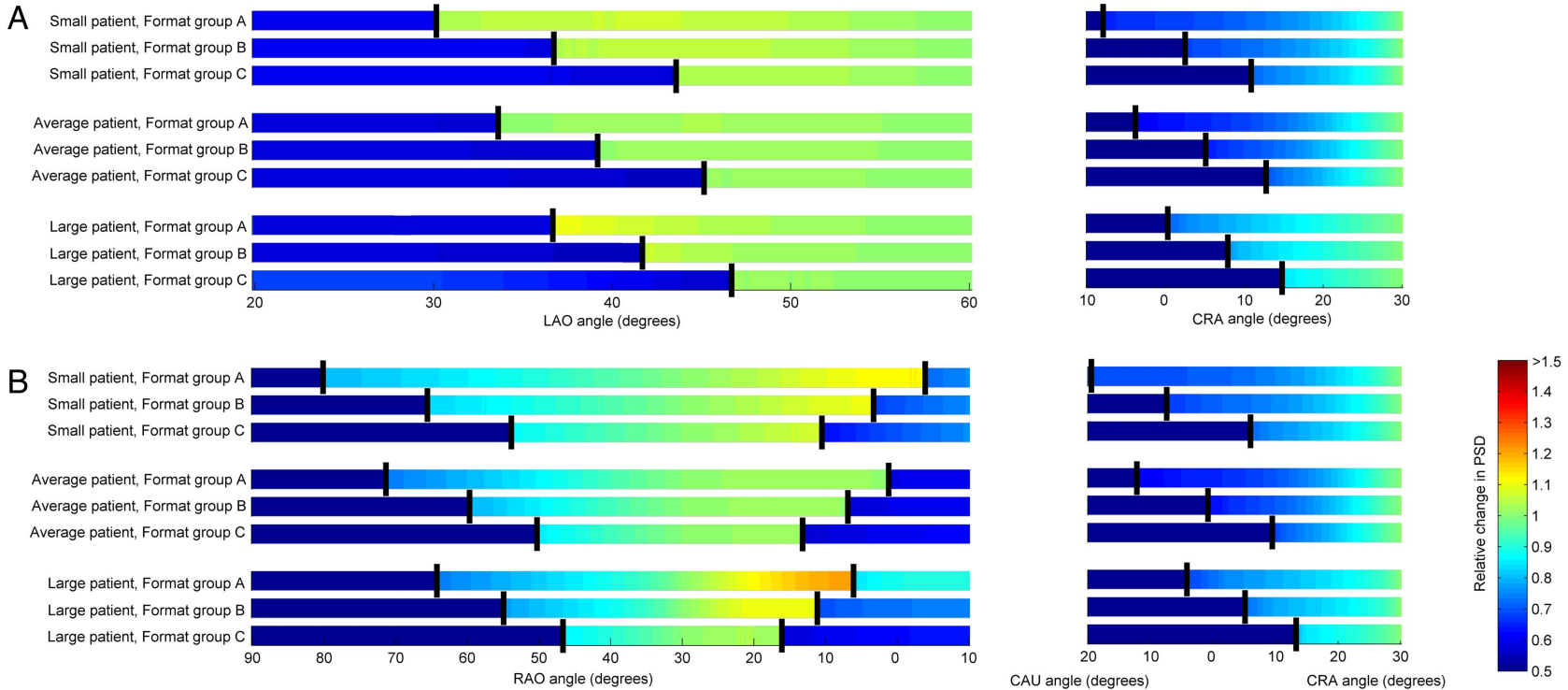

Figure 4 The effect of rotation from a primary compound projection on PSD for female patients: $(A)$ primary compound $60^{\circ}$ $\mathrm{LAO}+30^{\circ} \mathrm{CRA}$ projection and $(\mathrm{B})$ primary compound $30^{\circ} \mathrm{RAO}+30^{\circ} \mathrm{CRA}$ projection. Vertical bold lines indicating the AAO. The results for each format group representing the $X$-ray field format and size from the group that required the largest $A A O(A A O$, angle to avoid overlap; PSD, peak skin dose; CRA, cranial; LAO, left anterior oblique; PA, posteroanterior; RAO, right anterior oblique).

angles of up to $22^{\circ}$ were necessary to avoid overlap for small male and female patients (figure 5B) when large X-ray fields were used.

\section{DISCUSSION}

With a few exceptions, C-arm rotation was an effective strategy for reducing the PSD in simulated IC procedures, both as a procedural modification and a prophylactic measure. The effectiveness of this technique strongly depends on the format and size of the X-ray field, a finding that underscores the importance of collimation as an adjunct to $\mathrm{C}$-arm rotation. Tight collimation increases the benefit of $\mathrm{C}$-arm rotation in all scenarios, and has the added benefits of improving image contrast and reducing operator dose. Large patients, who are at highest risk for tissue effects, will benefit most from rotation of the $\mathrm{C}$-arm. Therefore, it can be reasonably assumed that $\mathrm{C}$-arm rotation is likely to minimise radiation induced skin injury in prolonged IC procedures, with maximal benefit derived on obese patients and in conjunction with tight collimation of the X-ray field.

Practical application of this method depends on the ability to achieve clinically useful imaging after rotating the C-arm to a new projection. PSD reduction is not likely to be achieved for small patients at useful angles. If there is no evidence to suggest that the procedure will be lengthy or complex, projections should be selected based on their clinical utility only. If the procedure
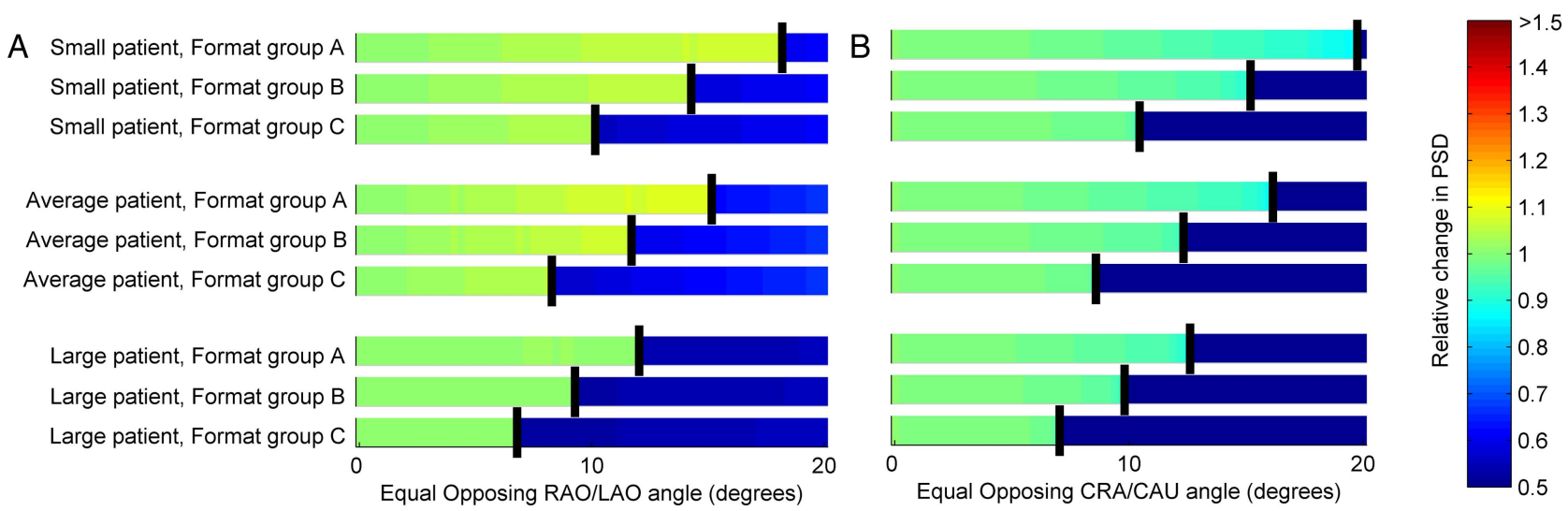

Figure 5 The effect of rotation between equal opposing projections on PSD for female patients: (A) LAO/RAO opposing projections and $(B)$ CRA/CAU opposing projections. The results for each format group representing the $X$-ray field format and size from the group that required the largest $A A O$ (AAO, angle to avoid overlap; PSD, peak skin dose; CAU, caudal; CRA, cranial; LAO, left anterior oblique; RAO, right anterior oblique). 

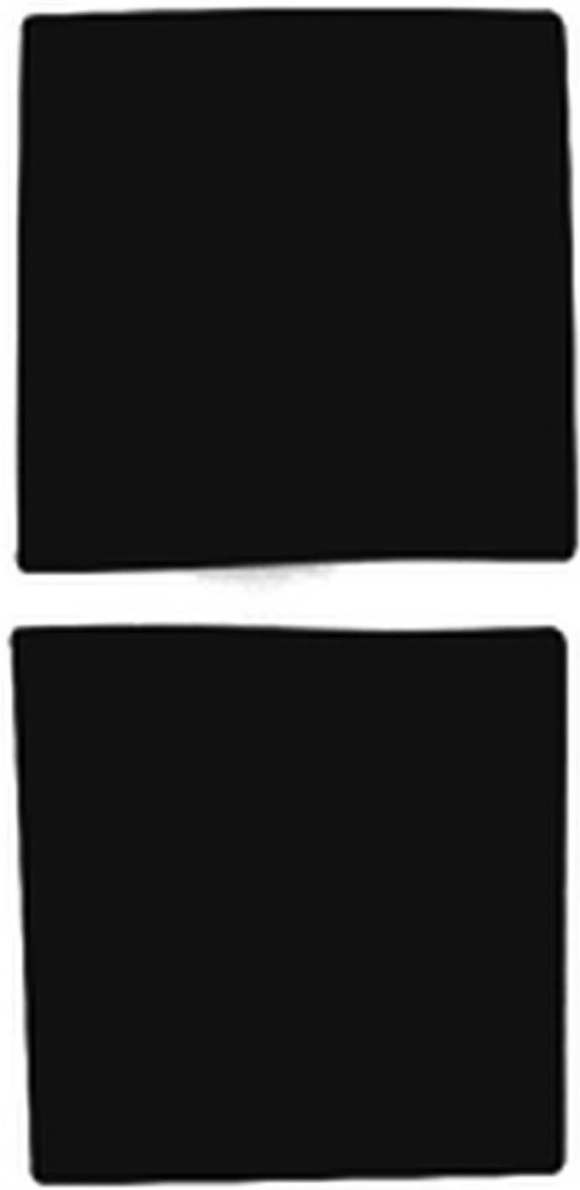

Figure 6 Exposed film demonstrating distinct radiation fields on the skin when the $\mathrm{C}$-arm was rotated between $12^{\circ} \mathrm{LAO}$ and $12^{\circ}$ RAO (16 cm field of view (FOV) on Artis zee, Format group $B$ ). The top of the image representing the right side of the anthropomorphic phantom representing a medium patient, and therefore irradiation at the $12^{\circ} \mathrm{LAO}$ angle. The window/ level was adjusted to clearly delineate the two fields (LAO, left anterior oblique; RAO, right anterior oblique).

becomes complicated, the results presented here can be used to identify approximate minimum rotation angles to reduce PSD. Rotation from a greater oblique angle to a lesser oblique angle will always reduce PSD, and if the obliquity of the projection must be increased, additional lateral rotation is preferred to additional CRA/CAU rotation.

If a procedure is expected to be lengthy, prophylactic rotation of the $\mathrm{C}$-arm between modest opposing angles in either the LAO/RAO or CRA/CAU direction can distribute dose between two distinct skin sites, reducing the PSD. Either $\mathrm{LAO} / \mathrm{RAO}$ or $\mathrm{CRA} / \mathrm{CAU}$ rotation was highly effective at reducing PSD (figure 6). Figure 5 can be used to determine the approximate angles required to implement this technique clinically.

One limitation of this study was the simulation of patients as elliptical cylinders. Although an elliptical cylinder is a reasonable representation of a patient's thorax, patients' tissues are redistributed when they lie on a patient support, resulting in deviation of the patient's shape from an ellipse. We have not compiled an exhaustive list of gantry configurations, and configurations other than those simulated in this study are used to perform IC procedures. Third, clinical implementation of the strategies discussed in this manuscript may not always be feasible, as rotation to certain angles may interfere with the goals of the procedure or may be impossible for very large patients.

These results should be viewed as general guidelines for the use of $\mathrm{C}$-arm rotation as a PSD reduction strategy in IC procedures. The physician performing the procedure must understand the effect of $\mathrm{C}$-arm rotation on PSD and how these effects vary based on patient size and $\mathrm{X}$-ray field size, then use these recommendations as a guide to reduce PSD when they do not interfere with the clinical goals of the procedure.

This simulation study confirmed the validity of C-arm rotation as a strategy for reducing PSD in FGI that use an isocentric geometry, such as IC. C-arm rotation is potentially most useful in large patients and in cases with prolonged radiation exposure such as complex PTCA, TAVR and EP procedures where the risks of radiation-induced tissue effects are highest. This technique can be utilised either prophylactically, or when practical, as a procedural modification. For procedural modification, lateral rotation is preferred over CRA/ CAU rotation, which in many circumstances can lead to an increase in PSD rate. Rotation between either opposing $\mathrm{LAO} / \mathrm{RAO}$ or CRA/CAU projections is an effective prophylactic approach to reduce PSD if commensurate with the diagnostic goals of the procedure. This technique offers the highest benefit for large patients. It is unlikely that reduction in PSD can be achieved for small patients at clinically acceptable angles. Other techniques known to reduce PSD can be used in synergy with C-arm rotation to achieve maximum reduction in skin dose. Tight collimation of the X-ray field increases the benefit of C-arm rotation, and has the added benefits of increasing image contrast and reducing patient and operator dose.

Competing interests None.

Ethics approval IRB.

Provenance and peer review Not commissioned; externally peer reviewed.

Open Access This is an Open Access article distributed in accordance with the Creative Commons Attribution Non Commercial (CC BY-NC 4.0) license, which permits others to distribute, remix, adapt, build upon this work noncommercially, and license their derivative works on different terms, provided the original work is properly cited and the use is non-commercial. See: http:// creativecommons.org/licenses/by-nc/4.0/

\section{REFERENCES}

1. Balter S, Hopewell JW, Miller DL, et al. Fluoroscopically guided interventional procedures: a review of radiation effects on patients' skin and hair. Radiology 2010;254:326-41.

2. Henry MF, Maender JL, Shen Y, et al. Fluoroscopy-induced chronic radiation dermatitis: A report of three cases. Dermatol Online $J$ 2009;15:354-8. 
3. Koenig TR, Mettler FA, Wagner LK. Skin injuries from fluoroscopically guided procedures: part 2, review of 73 cases and recommendations for minimizing dose delivered to patient. $A m \mathrm{~J}$ Roentgenol 2001;177:13-20.

4. Koenig TR, Wolff D, Mettler FA, et al. Skin injuries from fluoroscopically guided procedures: part 1 , characteristics of radiation injury. Am J Roentgenol 2001;177:3-11.

5. Shope TB. Radiation-induced skin injuries from fluoroscopy. Radiographics 1996;16:1195-9.

6. Wong L, Rehm J. Images in clinical medicine. Radiation injury from a fluoroscopic procedure. N Engl J Med 2004;350:e23-6.

7. De Olazo Banaag L, Carter MJ. Radionecrosis induced by cardiac imaging procedures: a case study of a 66-year-old diabetic male with several comorbidities. J Invasive Cardiol 2008;20:E233-6.

8. Rosamond W, Flegal K, Furie K, et al. Heart disease and stroke statistics-2008 update: a report from the American Heart Association Statistics Committee and Stroke Statistics Subcommittee. Circulation 2008;117:e25-146.

9. Balter S, Miller DL, Vano E, et al. A pilot study exploring the possibility of establishing guidance levels in x-ray directed interventional procedures. Med Phys 2008;35:673-80.

10. Neofotistou V. Review of patient dosimetry in cardiology. Rad Protect Dosim 2001;94:177-82.

11. Pantos I, Patatoukas G, Katritsis DG, et al. Patient radiation doses in interventional cardiology procedures. Curr Cardiol Rev 2009;5:1-11.

12. Daneault B, Balter S, Kodali SK, et al. Patient radiation exposure during transcatheter aortic valve replacement procedures. Eurolntervention 2012;8:679-84.

13. Hirshfeld JW Jr, Balter S, Brinker JA, et al. ACCF/AHA/HRS/SCA clinical competence statement on physician knowledge to optimize patient safety and image quality in fluoroscopically guided invasive cardiovascular procedures: a report of the American College of Cardiology Foundation/American Heart Association/American
College of Physicians Task Force on Clinical Competence and Training. Circulation 2005;111:511-32.

14. Limacher MC, Douglas PS, Germano G, et al. ACC expert consensus document. Radiation safety in the practice of cardiology. J Am Coll Cardiol 1998;31:892-913.

15. Stecker MS, Balter S, Towbin RB, et al. Guidelines for patient radiation dose management. J Vasc Interv Radiol 2009; 20:S263-73.

16. Wagner LK. Radiation injury is a potentially serious complication to fluoroscopically-guided complex interventions. Biomed Imag Interv 2007;3:e22-7.

17. Miller DL, Balter S, Noonan PT, et al. Minimizing radiation-induced skin injury in interventional radiology procedures. Radiology 2002;225:329-36.

18. Pasciak AS, Jones AK. Does "spreading" skin dose by rotating the C-arm during an intervention work? J Vasc Interv Radiol 2011;22:443-52.

19. Kuon E, Dahm J, Empen K, et al. Identification of less-irradiating tube angulations in invasive cardiology. J Am Coll Cardiol 2004;44:1420-8.

20. Cashwell ED, Everett CJ. A practical manual on the Monte Carlo method for random walk problems. 1st edn. New York: Pergamon Press, 1959.

21. Schultz C, Di Mario C. Optimal angiographic views for coronary angioplasty. In: Di Mario C, Dangas G, Barlis P, eds. Interventional cardiology: principles and practice. 1st edn. Hoboken: Blackwell Publishing Ltd, 2011:44-57.

22. Petoussi-Henss N, Zankl M, Drexler G, et al. Calculation of backscatter factors for diagnostic radiology using Monte Carlo methods. Phys Med Biol 1998;43:2237-50.

23. Geise RA, Peters NE, Dunnigan A, et al. Radiation doses during pediatric radiofrequency catheter ablation procedures. Pacing Clin Electrophysiol 1996;19:1605-11. 